\title{
Evaluation of Anxiolytic and Antibacterial Activity of Methanol Extract of Leaves of Mimosa pudica
}

\author{
Sharmin Sultana ${ }^{1, *}$, Md. Lokman Hossain ${ }^{2}$ \\ ${ }^{1}$ Pharmacy Discipline, Khulna University, Bangladesh \\ ${ }^{2}$ Department of Pharmacy, Stamford University Bangladesh, Bangladesh
}

Received September 1, 2019; Revised October 7, 2019; Accepted October 15, 2019

Copyright $@ 2019$ by authors, all rights reserved. Authors agree that this article remains permanently open access under the terms of the Creative Commons Attribution License 4.0 International License

\begin{abstract}
Background: Mimosa pudica belongs to the family of Mimosoideae. Traditional Chinese medicinal practitioners have long revered the bark, leaves and flowers of Mimosa for its potent health benefits. Limited modern scientific research has been conducted on the qualities of this plant. As part of our ongoing research of traditional medicinal plant, this study evaluated the anxiolytic and antibacterial activity of methanol extract of Mimosa pudica (MEMP) leaves. Method: The effect of MEMP on central nervous system (CNS) for anxiolytic activity was determined by mice light-dark box test, Elevated plus maze test and Hole board test. Disc diffusion assay was used to determine the antibacterial activity of MEMP. Result: Preliminary phytochemical screening revealed the presence of reducing sugar, tannin, glycoside, alkaloids and flavonoids. The present study demonstrated that MEMP showed significant anxiolytic $(p<0.05)$ effect at the doses of 200 and $400 \mathrm{mg} / \mathrm{kg}$ body weight in Light-dark box test, Elevated plus maze test. The movement of mice after administration of MEMP at doses of 200 and $400 \mathrm{mg} / \mathrm{kg}$ body weight decreased significantly in hole-board test, which indicated the high possibility of having anxiolytic activity. The MEMP showed dose-dependent antibacterial activity against the experimental bacterial strains namely Staphylococcus aureus, Staphylococcus epidermidis, Streptococcus agalactiae, Escherichia coli, and Shigella flexineri. Conclusion: The present study indicates that the MEMP extract possesses anxiolytic and antibacterial activity in a dose-dependent manner. Hence, the present work rationalizes the traditional uses of this plant. So, the plant may be further subjected to chemical investigation to isolate and purify the bioactive compound(s) responsible for its pharmacological activity.
\end{abstract}

Keywords Mimosa Pudica, Elevated Plus Maze Test, Light-Dark Box Test, Hole-Board Test, Disc Diffusion Assay

\section{Introduction}

The American Psychological Association (APA) defines anxiety as "an emotion characterized by feelings of tension, worried thoughts and physical changes like increased blood pressure." According to the World Health Organization (WHO), 1 in 13 globally suffers from anxiety. The WHO reports that anxiety disorders are the most common mental disorders worldwide with specific phobia, major depressive disorder and social phobia being the most common anxiety disorders. Treatment of anxiety consist of a combination of psychotherapy, behavioral therapy, and medication. Bacterial diseases are very common and contagious that can result in many serious or life-threatening complications, such as blood poisoning (bacteremia), kidney failure, and toxic shock syndrome.

Both primary and secondary phytoconstituents are ubiquitously present in the roots, leaves, shoots, flowers, vegetables and fruits of the medicinal plants that naturally exhibit defense mechanism, pharmacological activities i.e., anti-inflammatory, anticancer, anti-malarial, inhibition of cholesterol synthesis, anti-viral, anti-bacterial and ant-diabetic activities [1]. The worldwide demand for the practice of traditional medicine is escalating yearly. The reason behind this is that the medicines that the modern world offers right now are becoming resistant at a very high rate. Soon there will be no way out for us than to use the methods that have been used by our ancestors to heal our bodies. Around $60 \%$ of the pharmaceuticals are manufactured form plant origin.

Mimosa pudica is a sleepy sensitive herb that is found to be useful in alleviating the symptoms of hemorrhoids and acts as a natural astringent, displays antiseptic properties, and is said to impart a cooling effect. It encourages new hair cell growth, which may contribute in arresting hair loss. It also exhibits styptic activity, which can also help to stop bleeding in wounds and medical conditions like ulcerative colitis and menorrhagia. Due to its anti-inflammatory 
activity, people suffering from swollen joints may get relief by daily taking 1-3 mL tincture of $M$. pudica diluted with water [2]. Taking a decoction of the root of Mimosa pudica may be helpful for the treatment of urinary infections, particularly bladder stones [3].

As a part of our ongoing study of local medicinal plants of Bangladesh [4-10], here we evaluated the anxiolytic and antibacterial activity of methanol extract of Mimosa pudica leaves and examined its effectiveness whether it is effective against certain microbes and if it has antianxiety action.

\section{Materials and Methods}

\subsection{Collection of Plant Matetials}

The leaves of $M$. pudica were collected from Shukundi, Narsingdi, Dhaka, Bangladesh in August 2017. After that the plant was identified and verified by the senior scientific officer of Bangladesh National herbarium, Mirpur, Dhaka and the specified accession code was DACB: 45374.

\subsection{Preparation of Plant Extract}

The powdered dried leaves of Mimosa pudica (350 gm) was taken in a clean and flat-bottomed glass beaker and soaked in $4000 \mathrm{~mL}$ methanol (95\%) (Merck, Germany) at $25 \pm 2^{\circ} \mathrm{C}$ for seven days with regular shaking and stirring. After seven days, the solvent mixture was filtrated by a piece of sterile and white cotton material and finally by means of Whatman No. 1 filter paper. The solvent was completely removed by the operation of the rotary evaporator (BC-R201 Shanghai Biochemical Equipment Co. Ltd.) and obtained 10.25 gm extract (Yield 2.93\%).

\subsection{Collection and Maintenance of Animals}

Swiss-Albino mice of both male and female Swiss, aged 4-5 weeks, purchased from the animal breeding house of Jahangirnagar University, Savar, Dhaka, Bangladesh were used for the experiments. They were kept in standard environmental condition and fed International Center for Diarrhoeal Disease Research, Bangladesh (ICDDR, B) formulated food as per the international center of ICDDR, B. As these animals are very sensitive to environmental changes, they are kept before the test for at least 3-4 days in the laboratory. The animals were maintained under standard environmental conditions (temperature: $\left(24.0 \pm 1.0{ }^{\circ} \mathrm{C}\right)$, relative humidity: $55-65 \%$ and 12 hrs light/12 hrs dark cycle). Husk and excreta were removed from the cages on regular basis.

\subsection{Microorganisms}

Nine pathogenic bacterial strains (five Gram positive bacterial strains namely Staphylococcus aureus, Staphylococcus epidermidis, Staphylococcus pyogens, Streptococcus agalactiae, Enterococcus faecalis and four Gram negative bacteria Shigella flexneri, Shigella sonnei, Shigella boydigius, Escherichia coli) were used in this experiment. The experiment was conducted in Microbiology Laboratory of Department of Microbiology, Stamford University Bangladesh.

\subsection{Drugs and Chemicals}

The standard drugs Diazepam was collected from Incepta Pharmaceuticals Ltd. Dhaka, Bangladesh. Distilled water which was used for dilution purpose was obtained from Opsonin Pharma Limited.

\subsection{Phytochemical Screening}

The crude methanol extract of $M$. pudica leaves was qualitatively tested for the detection of alkaloids, glycosides, flavonoids, tannins, reducing sugar, carbohydrates, steroids and saponins following standard procedures [7].

\subsection{Determination Anxiolytic Activity}

The effects of drugs on the central nervous system CNS with reference to the neurotransmitters for specific circuits, attenuation should be developed to general organizational principles of neurons. The view that synapses represent drug-modifiable control points within neuronal networks. It requires explicit delineation of the sites at which given neurotransmitters may operate and the degree of specificity with which such site that may be affected [11].

\subsubsection{Elevated Plus-Maze Test}

The Elevated Plus Maze (EPM) test consisted of two open arms $(30 \times 5 \times 0.25 \mathrm{~cm})$ and two closed arms $(30 \times 5$ $\times 15 \mathrm{~cm})$ emanating from a common central platform $(5 \times 5$ $\mathrm{cm})$. Two pairs of same arms were opposite to each other. The entire apparatus was elevated to a height of $40 \mathrm{~cm}$ above floor level. At the beginning of the session, a mouse was placed at the center of the maze, its head facing an open arm and allowed to explore the maze for 5 minutes, and the following parameters were scored: the time spent and number of entries in each type of arms. The plus maze was carefully cleaned with a wet towel after each animal test. The mice were divided into four groups (5 mice/group). The control group received vehicle (distilled water $0.1 \mathrm{~mL} / \mathrm{mice}$ ). Diazepam (1 $\mathrm{mg} / \mathrm{kg}$ b.w., IP) was used as the positive control or standard group and MEMP extract at the doses of 200 and $400 \mathrm{mg} / \mathrm{kg}$ body weight, orally, in the two remaining groups. After each trial, the EPM apparatus was wiped clean with alcohol (70\%) Solution [12].

\subsubsection{Light-Dark Box Test}

The apparatus $(45 \times 21 \times 21 \mathrm{~cm})$ consisted of two 
compartments with one third painted white and two thirds painted black, and these compartments were parted by a divider with a $3.5 \times 3.5 \mathrm{~cm}$ opening at floor level. The small compartment was painted black and illuminated by a $\operatorname{dim}$ red light $(60 \mathrm{~W} ; 4 \mathrm{~lx})$, whereas the large compartment was painted white and brightly illuminated with a 60-W (400 lx) light source. The compartments were equipped with infrared beam sensors (four in the white area, three in the black one). Each mouse was tested by placing it in the center of the white area, facing away from the dark one, and was allowed to explore the novel environment for $5 \mathrm{~min}$ and thereby enabling the detection of locomotion in each zone, time spent in each zone, latency of the first crossing from one compartment to the other, and shuttle crossings between both compartments. The data for these four parameters were directly collected by observer. This test exploited the conflict between the animal's tendency to explore a new environment and its fear of bright light $[13,14]$. The mice were distributed into four groups (5 mice/group). The control group received vehicle (saline water $0.1 \mathrm{~mL} /$ mice). Diazepam was used as the positive control or standard group and MEMP extract at the doses of 200 and $400 \mathrm{mg} / \mathrm{kg}$ body weight, orally (two groups).

\subsubsection{Hole-Board Test}

The hole-board apparatus consists of a gray wooden box $(40 \times 40 \mathrm{~cm}, 2.2 \mathrm{~cm}$ thick) having 16 equidistant holes $3 \mathrm{~cm}$ in diameter in the floor. Animals were kept in a quiet laboratory before this experiment, at least, one hour prior to testing. Each animal was placed singly in the center of the board opposite the observer and the number of head dipping into the hole was recorded over a 5 minutes exploration period on the board. Head dipping was recorded only when both eyes disappeared into the hole [15]. The mice were divided into four groups (5 mice/group). The control group received vehicle and Diazepam was used as the positive control or standard group and MEMP extract at the doses of 200 and 400 $\mathrm{mg} / \mathrm{kg}$ body weight, orally, in the two rest groups.

\subsection{Antibacterial Activity Test}

Antibacterial activity test was determined by disc diffusion method [16]. Sample at 250 and $500 \mu \mathrm{g} /$ disc, Kanamycin at $30 \mu \mathrm{g} / \mathrm{disc}$ and methanol at $10 \mu \mathrm{L} / \mathrm{disc}$ as negative control was applied in this study. The growth media was prepared in aseptic condition and poured into petridishes.

\subsection{Statistical Analysis}

Results were expressed as mean \pm S.E.M. Variance was analyzed using One-way Analysis Of Variance (ANOVA), followed by Newman-Keul's multiple comparisons test. P $<0.05$ was considered to be statistically significant.

\section{Results}

\subsection{Preliminary Qualitative Phytochemical Analysis}

Preliminary phytochemical screening of MEMP showed the presence of reducing sugar, tannins, glycoside, alkaloids and flavonoids (Table 1 ).

Table 1. Result of Phytochemical group test

\begin{tabular}{|c|c|}
\hline Phytoconstituents & Result \\
\hline Reducing sugar & + \\
\hline Tannins & + \\
\hline Flavonoids & + \\
\hline Terpenoids & - \\
\hline Saponin & - \\
\hline Steroids & - \\
\hline Alkaloids & + \\
\hline Gums & - \\
\hline Glycosides & + \\
\hline Protein & - \\
\hline
\end{tabular}

+ = Presence, - = Absence

\subsection{Elevated Plus Maze Test}

In EPM, the methanol extract of the leaves of Mimosa pudica was tested at the doses of 200 and $400 \mathrm{mg} / \mathrm{kg}$ body weight. If the MEMP had anxiolytic effect the time spent in open arm would rise gradually and time spent in closed arm would decrease gradually. The results presented in table 2 indicate that treating mice with MEMP at the doses of 200 and $400 \mathrm{mg} / \mathrm{kg}$ body weight increased the percentage of time spent in open arm compared with the control group. In addition, diazepam (1 mg/kg body weight) as a widely used anxiolytic drug in clinical practice significantly increased the percentage of time spent in the open arms in the EPM. Conversely, the number of entries and the time spent in the closed arms were reduced (Table 2).

Table 2. Effect of MEMP on mice in spent time in open and closed arm

\begin{tabular}{|c|c|c|c|}
\hline Treatment & Dose $(\mathrm{mg} / \mathrm{kg}$ b.w.) & Time in open arm (sec) & Time in closed arm (sec) \\
\hline Control & $0.1 \mathrm{~mL} / \mathrm{mice}$ & $13 \pm 0.89$ & $287 \pm 0.89$ \\
\hline Standard & $1 \mathrm{mg} / \mathrm{kg}$ & $47.6 \pm 1.017^{*}$ & $246.2 \pm 1.017^{*}$ \\
\hline MEMP & $200 \mathrm{mg} / \mathrm{kg}$ & $27.2 \pm 0.49^{*}$ & $268.3 \pm 0.49^{*}$ \\
\hline MEMP & $400 \mathrm{mg} / \mathrm{kg}$ & $77.7 \pm 0.84^{*}$ & $231.2 \pm 0.84^{*}$ \\
\hline
\end{tabular}

Values are expressed as Mean \pm SEM ( $n=5)$;

$* \mathrm{P}<0.05$ compared with the control group (Dunnett's Test) 


\subsection{Light-Dark Box Test}

In LDB, the methanol extract of $M$. pudica was tested at the doses of $200 \mathrm{and} 400 \mathrm{mg} / \mathrm{kg}$ body weight. If the MEMP had anxiolytic effect, the time spent in light area would rise progressively and time spent in dark area would decrease gradually. The results presented in table 3 indicate that treating mice with MEMP at the doses of $200 \mathrm{and} 400 \mathrm{mg} / \mathrm{kg}$ body weight increased the percentage of time spent in light area compared with the control group. In addition, diazepam ( $1 \mathrm{mg} / \mathrm{kg}$ body weight) as a widely used anxiolytic drug, significantly increased the percentage of time spent in the light area in the LDB (Table 3). This result is comparable to the reference drug, diazepam.

Table 3. Effect of MEMP on mice in spent time in light and dark area

\begin{tabular}{|c|c|c|c|}
\hline Treatment & Dose (mg/kg b.w.) & Time in light area (sec) & Time in dark area (sec) \\
\hline Control & $0.1 \mathrm{~mL} / \mathrm{mice}$ & $60.8 \pm 0.58$ & $272.1 \pm 0.59$ \\
\hline Standard & $1 \mathrm{mg} / \mathrm{kg}$ & $256.5 \pm 1.15^{*}$ & $48.4 \pm 1.15^{*}$ \\
\hline MEMP & $200 \mathrm{mg} / \mathrm{kg}$ & $90.0 \pm 1.47^{*}$ & $198.0 \pm 1.48^{*}$ \\
\hline MEMP & $400 \mathrm{mg} / \mathrm{kg}$ & $121.3 \pm 2.14^{*}$ & $171.6 \pm 2.17^{*}$ \\
\hline
\end{tabular}

Values are expressed as Mean \pm SEM $(n=5)$;

$* \mathrm{P}<0.05$ compared with the control group (Dunnett’s Test)

\subsection{Hole-Board Test}

In the hole board test, pre-treatment with diazepam significantly decreased $(\mathrm{p}<0.05)$ number of head dipping when compared to the control. Also, pre-treatment with MEMP at the doses of 200 and $400 \mathrm{mg} / \mathrm{kg}$ body weight also significantly decreased the number of head dipping, when compared to the control group. It can be said that MEMP possesses CNS effect which is comparable to diazepam (Table 4).

Table 4. Effect of MEMP on mice in hole-board test

\begin{tabular}{|c|c|c|}
\hline Treatment & Dose and Route & No. of Head Dipping into hole \\
\hline Control & $0.1 \mathrm{~mL}$, Oral & $58.2 \pm 1.31$ \\
\hline Standard & $1 \mathrm{mg} / \mathrm{kg}$, i.p. & $25.0 \pm 1.28^{*}$ \\
\hline MEMP & $200 \mathrm{mg} / \mathrm{kg}$, Oral & $61.3 \pm 1.02^{*}$ \\
\hline MEMP & $400 \mathrm{mg} / \mathrm{kg}$, Oral & $40.7 \pm 1.24^{*}$ \\
\hline
\end{tabular}

Values are expressed as Mean \pm SEM ( $\mathrm{n}=5)$;

$* \mathrm{P}<0.05$ compared with the control group (Dunnett’s Test)

\subsection{Antibacterial Activity Test}

The methanol extract of M. pudica showed antibacterial activity against Staphylococcus aureus, Staphylococcus epidermidis, Streptococcus agalactiae, Escherichia coli, Shigella flexineri. At the dose of 250 and $500 \mu \mathrm{g} / \mathrm{disc}$, it showed maximum activity (8.94 mm and $15.89 \mathrm{~mm}$, respectively) against Escherichia coli (Table 5).

Table 5. Antibacterial activity of MEMP by disc diffusion assay

\begin{tabular}{|c|c|c|c|c|c|}
\hline \multirow{3}{*}{ Bacterial Strains } & \multirow{3}{*}{$\begin{array}{c}\text { Type of } \\
\text { Bacterial } \\
\text { Strains }\end{array}$} & \multicolumn{4}{|c|}{ Diameter of Zone of Inhibition in $\mathrm{mm} \pm$ S.E. } \\
\hline & & \multirow{2}{*}{ Control } & \multicolumn{2}{|c|}{ Mimosa pudica (Dose/disc) } & \multirow{2}{*}{$\begin{array}{l}\text { Kanamycin (30 } \\
\mu \mathrm{g} / \text { disc) }\end{array}$} \\
\hline & & & $250 \mu \mathrm{g}$ & $500 \mu \mathrm{g}$ & \\
\hline Staphylococcus aureus & Gram(+ve) & 0 & $7.48 \pm 0.59$ & $14.12 \pm 0.71$ & $28.05 \pm 0.68$ \\
\hline Staphylococcus epidermidis & Gram(+ve) & 0 & $8.02 \pm 0.86$ & $15.64 \pm 0.76$ & $26.27 \pm 0.55$ \\
\hline Staphylococcus pyogens & Gram(+ve) & 0 & 0 & 0 & $30.05 \pm 0.74$ \\
\hline Streptococcus agalactiae & Gram(+ve) & 0 & $6.91 \pm 0.95$ & $12.36 \pm 0.91$ & $21.28 \pm 0.89$ \\
\hline Enterococcus faecalis & Gram(+ve) & 0 & 0 & 0 & $30.07 \pm 0.71$ \\
\hline Shigella sonnei & Gram(-ve) & 0 & 0 & 0 & $30.45 \pm 0.89$ \\
\hline Shigella boydigius & Gram(-ve) & 0 & 0 & 0 & $17.55 \pm 0.89$ \\
\hline Escherichia coli & Gram(-ve) & 0 & $8.94 \pm 0.90$ & $15.89 \pm 0.99$ & $28.79 \pm 0.94$ \\
\hline Shigella flexineri & Gram(-ve) & 0 & $6.52 \pm 0.78$ & $11.48 \pm 0.77$ & $23.33 \pm 0.83$ \\
\hline
\end{tabular}

Gram (+ve) = Gram Positive Bacteria, Gram (-ve) = Gram Negative Bacteria, 0= No Inhibition 


\section{Discussion}

The etiology of most anxiety disorders are not fully understood, but numerous studies have revealed the involvement of GABAergic and serotonergic neurotransmission in etiology, expression and treatment of anxiety. Benzodiazepines (BZDs), barbiturates, Tricyclic antidepressants (TCA's) have been used for long time to treat anxiety disorders. The serious side effects linked with these drugs, namely rebound insomnia, sedation, muscle relaxation, withdrawal and tolerance (BZD's, barbiturates and alcohol), sexual dysfunction, anticholinergic, antihistaminic effects (TCA's) have limited their use in patients. Buspirone, the non-sedative anxiolytic agent is not effective in a high percentage of patients. It is also associated with tachycardia, palpitation, gastric discomfort [15].

The anxiolytic effect of Mimosa pudica leaves was revealed by the elevated plus maze, light-dark box and hole-board test. The present study indicates that oral administration of MEMP elicits a potent and dose-dependent anxiolytic effect.

The elevated plus maze is a widely used behavioral model in mice and has been validated to investigate the anxiolytic potential of different pharmacological agents [17]. The open arm activities of the animals in EPM reflect a conflict between the mice native behavior to retain itself in a protected area (e.g., closed arms) and motivation to explore in a novel environment, where the anxiolytic agents induce the exploratory activities of the mice in the open arm [18]. If the MEMP had anxiolytic effect the time spent in open arm would rise gradually and time spent in closed arm would decrease gradually and the experimental data exhibited same consequence. So, the effects treatment of mice with MEMP on time spent in open and time spent in close arm were significant, which indicates a possible anxiolytic properties of MEMP.

Light-dark box test is also widely used for mice as a model for screening anxiolytic or anxiogenic drugs, based on the innate aversion of animals to brightly illuminated areas and on the spontaneous exploratory behavior of mice in response to mild stressors, that is, a new environment and light [19]. It has been stated that simply the measurement of the time spent in the light area, but not the number of transfers, is the most consistent and useful parameter for assessing an anxiolytic action [20]. However, the effects of treatment of mice with MEMP on Latency time and time spent in light, no of transition. If the MEMP had anxiolytic effect the time spent in light area would rise steadily and time spent in dark area would decrease steadily and the experimental data showed this exact scenario. So, the effects of treatment of mice with MEMP on time spent in light and time spent in dark area were statistically significant, which indicates of having possibility of anxiolytic properties of MEMP.

The present data demonstrate that in the hole-board test, the number of head-dips by the mice administered with 200 and $400 \mathrm{mg} / \mathrm{kg}$ body weight is comparable with results from diazepam treated group. In hole board test, pre-treatment with diazepam significantly decreased $(p<0.05)$ number of head dipping when compared to the control. Also, pre-treatment with MEMP at doses of 200 and $400 \mathrm{mg} / \mathrm{kg}$ body weight also reduced the number of head dipping, which directs of having possibility anxiolytic properties of MEMP. The most important step in evaluating drug action on the CNS is to observe the behavior of the test animals. This consequences in net reduction of excitatory synaptic transmission.

Anxiolytics (e.g. diazepam) are known to exert their pharmacological action by increasing the gamma aminobutyric acid (GABA) content of mice cerebral hemisphere. Further neuropharmacological studies should be vital to ascertain if Mimosa pudica actually mediates its action via similar mechanism [14].

The phytochemicals of flavonoids, polyphenols and tannins, quinones, terpenoids and essential oils and alkaloids show antimicrobial activity [21]. Flavonoids showed antibacterial activity by complexing with cell wall and also binds to adhesions. Tannins may protect plants from invasion of pathogenic microorganism due to their antimicrobial and antifungal properties [22]. Polyphenols and tannins exert antimicrobial activity through following mechanism -binds to adhesions, enzyme inhibition and substrate deprivation, complex with cell wall, membrane disruption and metal ion complexation. Alkaloids exert antimicrobial activity through intercalating into cell wall and DNA of parasites [21]. MEMP was effective against gram positive and gram negative bacteria but gram negative ones are most sensitive. Also in the present study extract showed dose dependent antibacterial activity and more effective against gram negative bacteria compared to gram positive bacteria. Phytochemical groups namely flavonoids, alkaloids and tannins may be responsible for antibacterial activity.

\section{Conclusions}

The methanol extract of Mimosa pudica has significant anxiolytic and antibacterial effect. The effect is dosedependent and statistically significant. However, further studies are needed to isolate the pharmacologically active compound(s) responsible for these activities.

\section{Acknowledgement}

The authors are grateful to the Laboratory of Pharmacognosy and Pharmacology, Department of Pharmacy and Microbiology Laboratory, Department of Microbiology, Stamford University Bangladesh, Dhaka for providing all supports to carryout of this research. 


\section{Approval of Animal Ethics Committee}

All the experimental mice were treated following the Ethical Principles and Guidelines for Scientific Experiments on Animals (1995) postulated by the Swiss Academy of Medical Sciences and the Swiss Academy of Sciences. The Institutional Animal Ethical Committee (SUB/TAEC/11.01) of Stamford University Bangladesh permitted all experimental rules.

\section{REFERENCES}

[1] Wadood A., Ghufran M., Jamal S. B., Naeem M., Khan A., Ghaffar R., Asnad. Phytochemical Analysis of Medicinal Plants Occurring in Local Area of Mardan. Biochem. Anal. Biochem, 2:4. 2/2161-1009.1000144. 2013; 2(4).

[2] Yu Z. F., Kong L. D., Chen Y. Antidepressant activity of aqueous extracts of Curcuma longa in mice: Ethnopharmocol, 83: 161; 2002.

[3] Antai-Otong D. Anti-depressant-induced insomnia: Treatment options. Perspect Psych Care. 40:29-33; 2004.

[4] Aliza, Sultana S., Hossain M. L. In vivo Assessment of Neuropharmacological Activity of Methanol Leaves Extract of Callicarpa arborea (Family: Verbenaceae) in Swiss albino Mice. Sch Int J Tradit Complement Med. 2019, 2(6): 85-89.

[5] Smrity K. K., Sultana S., Hassan M. A., Hossain M. L. Medicinal activity of Vitex negundo L. (Family: Lamiaceae) leaves extract: Assessment of phytochemical and pharmacological properties. J. Pharmacogn. Phytochem. 2019, 8 (3), 3571-3575.

[6] Hossain M. L., Sultana S. In-vivo Assessment of Neuropharmacological Activity of Methanol Bark Extract of Mimosa pudica in Mice. Adv. Pharmacol. Pharm. 2019, $7(2), 33-37$

[7] Karmakar U. K., Sultana S., Nishi S., Biswas N. N., Hossain L., Sheikh S. Antioxidant, Analgesic, Antimicrobial, and Anthelmintic Activity of the Dried Seeds of Bixa orellana (L). Int. J. Pharm. 2018, 8 (1), 150-163.

[8] Khushi S., Hasan M. M., Monjur-Al-Hossain A. S. M., Hossain M. L., Sadhu S. K. Medicinal Activity of Avicennia officinalis: Evaluation of Phytochemical and Pharmacological Properties. Saudi J. Med. Pharm. Sci. 2016, 2 (9), 250-255.

[9] Fahad S. M., Islam A. F. M., Ahmed M., Uddin N., Alam M. R., Khalik M. F., Hossain M. L., Abedin M. J. Determination of elemental composition of Malabar spinach, lettuce, spinach, hyacinth bean, and cauliflower vegetables using proton induced $\mathrm{X}$-ray emission technique at Savar subdistrict in Bangladesh. BioMed. Res. Int. 2015, 2015, 1-11.

[10] Hossain M. L., Monjur-Al-Hossain A. S. M., Sadhu S. K. HPLC Profiling and Evaluation of Invitro Antioxidant Activity of Cirsium arvense L. (Family: Asteraceae). J.
Pharmacogn. Phytochem. 2016, 5 (1), 272-277.

[11] Basak A., Hossain M. L., Parvin M. N. Evaluation of phytochemical and pharmacological activities of Bacopa monnieri (L.). Int. J. Sci. Rep. 2016, 2 (10), 242-247.

[12] Almeida E. R., Rafael K. R. O., Couto G. B. L., Ishigami A. B. M. Anxiolytic and Anticonvulsant Effects on Mice of Flavonoids, Linalool, and -Tocopherol Presents in the Extract of Leaves of Cissus sicyoides L. (Vitaceae), Journal of Biomedicine and Biotechnology, 2009 (2009), Article ID 274740.

[13] Hascoet M., Bourin M. A new approach to the light/dark test procedure in mice. Pharmacol., Biochem. Behav. 2009; 60(3):645-653.

[14] Petra M. A., Ipponi A., Bartolini A., Schunack W. Mouse light/dark box test reveals anxiogenic-like effects by activation of histamine $\mathrm{H} 1$ receptors. Pharmacol., Biochem. Behav.. 2002; 71, 313-318.

[15] S. Onasanwo A., Faborode S. O., Agrawal M., Ijiwola O. L., Jaiyesimi B. O., Narender T. Antidepressant and Anxiolytic Potentials of Chebulinic Acid in Laboratory Rodent, Austin Publishing Group, Ann Depress Anxiety . 2014, 1 (7).

[16] Ahmed F., Das P. K., Islam M. A., Rahman K. M., Rahman M. M., Selim M. S. T. Antibacterial activity of Cordyline terminalis. Kunth. leaves. J. Med Sci. 2003; 3(5-6): 418422.

[17] Thakur V. D., Mengi S. A. Neuropharmacological profile of Eclipta alba (Linn.) Hassk. Ethnopharmacol, 2005; 102: 23-31.

[18] Walf A. A., Frye C. A. The use of the elevated plus maze as an assay of anxiety-related behavior in rodents, Nature Protocols, 2007; 2, (2):322-328.

[19] Pellow S., Chopin P., File S. E., Briley M. Validation of open: closed arm entries in an elevated plus-maze as a measure of anxiety in the rat. Journal of Neuroscience Methods. 1985; 14(3):149-167.

[20] Imaizumi M., Suzuki T., Machida H., Nodera A. Fully automated apparatus for a light/dark test measuring anxiolytic or anxiogenic effects of drugs in mice. Jpn. J. Psychopharmacol. 1994; 14:83-91.

[21] Prashant T., Bimlesh K., Mandeep K., Gurpreet K., Harleen K. Phytochemical screening and Extraction: A Review, Internationale Pharmaceutica Sciencia. 2011; 1(1): 98-106.

[22] Silanikove N., Prevolotsky A., Provenga F. D. Use of tannin-binding chemicals to assay for tannins and their negative postingestive effects in ruminants. Anim. Feed Sci. Technol. 2001;91(1): 69-81. 